\title{
Behavioural thermoregulation of alpine birds in response to low temperature in early summer
}

\author{
You Zhou, Ainsley Maurer, Tanja Cobden, Yvonne Yong, \\ Ray Zhang, Gregory Gauthier-Coles, Caitlin McLeod, \\ Cynthia Turnbull
}

\section{Abstract}

Thermoregulation in animals can be achieved physiologically and behaviourally. Alpine birds can obtain significant radiation benefits from the sun and to help conserve heat they adjust their behaviours such as perching. The aim of this study was to explore the preferences of alpine birds for temperature and illumination of perching sites. We measured the temperature and light intensity of both potential sites and actual sites where birds perched, and compared the distributions of temperature and illumination of these on cold and warm days among species. Results showed a non-random selection of temperatures on cold days and a slightly higher light preference on warm days. Among species, only the little raven (Corvus mellori) showed a preference for warmer and lighter perching sites, while other species either showed no predilection or perched in warmer places due to other factors of habitat selection. When perching, behaviours like sitting (hiding feet) and puffing were more frequent on cold days and no birds chose a shady site when the temperature was low. The influence of predation may explain the random selection of perch site in most birds. Finally, the results indicate that alpine birds may be more favoured by the warming of the alpine region. 


\section{Introduction}

Thermoregulation, the adjustment of body temperature, is one of the most important metabolic activities in both ectotherms and endotherms (Tansey and Johnson 2015). Maintaining body temperature is fundamental for the majority of metabolic processes as the enzymes that are involved are sensitive to temperature (DiBona 2003). Thermal neutrality is found in endotherms, in which an organism invests the minimal energy to regulate body temperate. Beyond a particular range of ambient temperature, called the thermal neutral zone, organisms have to pay extra costs to adjust; they use behaviours such as evaporative cooling when higher than the upper critical temperature and shivering when lower are commonly found (Zhao et al. 2014). Because of their higher body temperature and basal metabolic rate, birds have relatively higher thermal neutral zones than mammals (Toro-Velasquez et al. 2014).

Thermoregulation can be achieved by physiological and behavioural activities, including vasoconstriction, vasodilation and hormone adjustments. Birds can physiologically maintain their body temperature by adjusting their circulatory system, like the concurrent blood flow in penguin feet on ice and heat exchange from the toucan bill, yet evidence shows that birds also have complex behaviours responding to unfavourable temperatures (Durfee 2008; Tattersall et al. 2009). Several studies suggested that lizards employ basking behaviours for heating and, similarly, birds use radiation from the sun when the ambient temperature is low (Dzialowski and O'Connor 2001). To maintain heat, chickens usually fluff out feathers when standing still, and many small birds huddle in groups; other heat-retaining behaviours such as spreading wings and facing the sun are also found in most avian species (Hafez 1964).

However, there is always a trade-off between thermal benefit and predation risk when perching in the sun, as illumination from the sun is not only linked with heat radiation but also exposes organisms to predators. 'Disability glare' in high light environment may also lead to a delayed response to predators and therefore some birds, like brownheaded cowbirds (Molothrus ater), show a preference for shade rather than sunny areas for foraging (Fernández-Juricic et al. 2012). However, because exposure to sunlight significantly decreases metabolic rate, and some birds, such as sunbirds, prefer to forage in the sun (Carr and Lima 2014). 
Low temperature and high light are typical characteristics of alpine region, which provides a variety of challenges for local animals. The environment is especially harsh for birds because of their relatively high energetic and thermal requirements, and smaller birds have even higher energy requirements due to their higher surface area to volume ratio (Carrascal et al. 2001). The behavioural thermoregulation of alpine birds is not well known, especially in early summer when most of predators are active but temperature is still low. In this study, we observed and analysed the thermoregulation behaviour of birds in the alpine region, testing the impact of temperature and illumination for perch-site choice among different species. We predicted that birds would prefer warm and high light perching sites, and small birds would prefer a warm and high light site to a greater extent than large birds as smaller birds are quicker to lose heat.

\section{Materials and methods}

\section{Study site and species}

Our study site was located around the Southern Alps Lodge in Charlotte Pass, New South Wales, Australia. The study site was $300 \mathrm{~m}$ in diameter and the elevation was $1,783 \mathrm{~m}$ above sea level. The site was a mixture of snow gum forest and grassland, most of which was impacted by human activities.

The bird species we mainly focused on was the little raven (Corvus mellori) with an average mass of $428 \mathrm{~g}$. We also observed the behaviour of crimson rosellas (Platycercus elegans, $127 \mathrm{~g}$ ), common starlings (Sturnus vulgaris, $80 \mathrm{~g}$ ) and flame robins (Petroica phoenicea, $14 \mathrm{~g}$ ). The thermal neutral zone of common starlings is $28-37^{\circ} \mathrm{C}$ (Dmi'el and Tel-Tzur 1985) and 18 $32^{\circ} \mathrm{C}$ for crimson rosellas (McNab and Salisbury 1995). Thermal neutral zones of the little raven (Corvus mellori) and flame robin (P. phoenicea) are unknown, but the brown-necked raven (Corvus rificollis), in the same genus as the little raven, has a neutral zone of $30-37^{\circ} \mathrm{C}$ (Marder 1973).

Experimental observations were made in early summer, between 14 and 16 December 2015. We went out birdwatching on both the morning and afternoon of 14 December, which was a sunny and relatively warm day. On the following two days, data were only collected in the mornings, and the weather was cold on both days: 15 December was cloudy while 16 December followed a rainy night. We treated 14 December as a warm day and 15 and 16 December as cold days. 


\section{Field observation}

To explore the conditions of the environment, background readings were made continuously during field observation. Every 3 minutes, two nearby objects were randomly selected as potential perching sites, and temperature and light intensity were measured with a thermal gun (GM320 infrared thermometer) and light meter (Sanwa illuminance meter LX2). The type of object (branch, grass, rock, shrub), temperature $\left({ }^{\circ} \mathrm{C}\right)$, light intensity (Klux) and time were recorded.

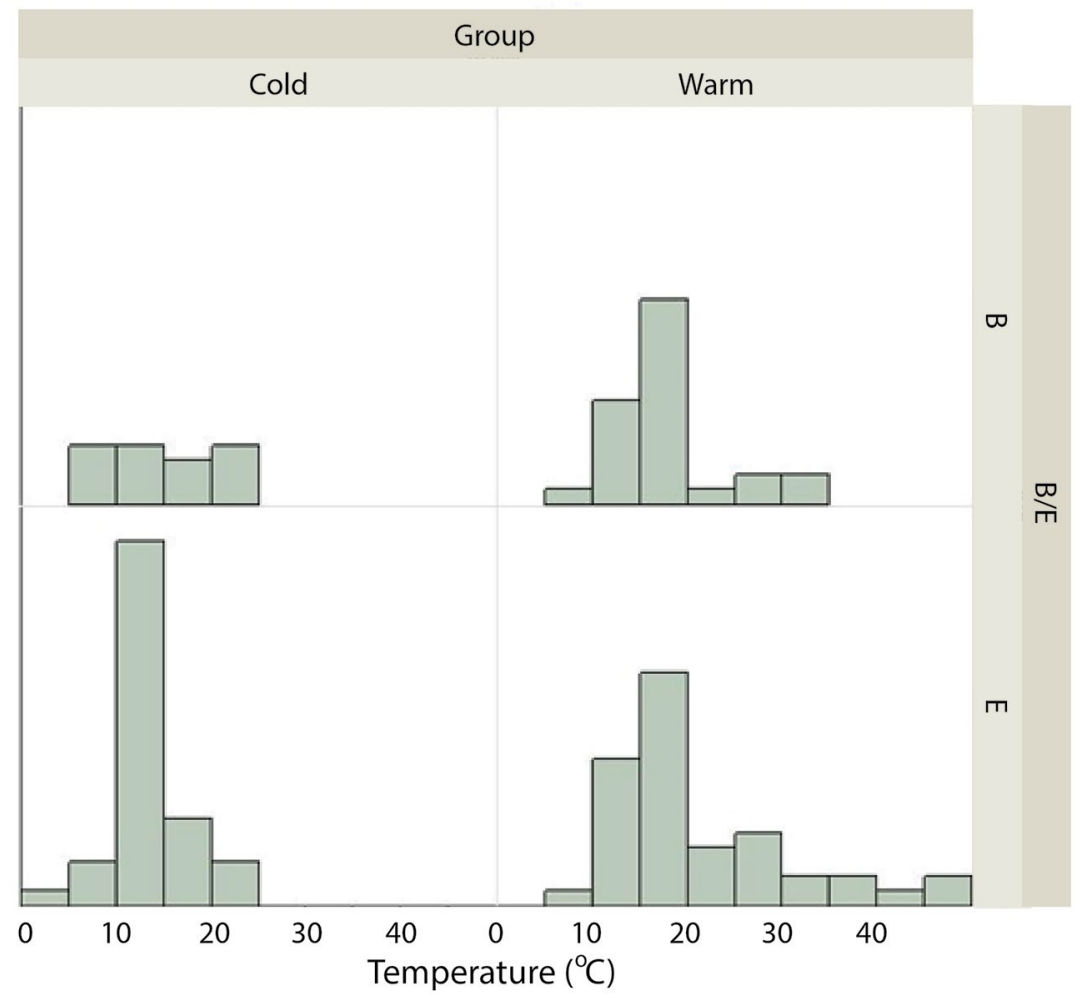

Figure 1: Frequency histogram of temperature comparing perch site and environment on cold and warm days. B represents bird perch site while E represents environment (background reading). Temperature, which was measured by thermal gun, was divided into $5^{\circ} \mathrm{C}$ intervals (in $\mathrm{x}$-axis) and the height of the column represents the frequency of the object temperature. By comparing the temperature distribution of perch site and environment, it is suggested that birds have no preference based on temperature during warm days but do not randomly select perch site on cold days.

Source: Authors' data. 
For birdwatching, those large birds such as ravens, rosellas and starlings that were observed to be sitting for 35 seconds or longer were considered to be perching, while the time threshold for small birds (e.g. robins) was 20 seconds. Temperature of the perching site was measured using a thermal gun or thermal camera (FLIR T420) and light intensity was measured using a light meter. If the perch site was high up in the tree and out of the range of the measuring instrument, the temperature and light immediately beneath the perch site was assumed to be the same and was recorded. Also, time, species, location and the description of bird behaviour (puffing the feathers, sitting with legs hidden, perch in the shade/sun) was recorded.

\section{Data analysis and statistics}

Temperature data of thermal images were analysed by FLIR software. The pixels of the perch site were recorded as well as four random spots in the vicinity of the site, which included above, below, left and right of where the bird was. The nearby spots were recorded for microenvironment analysis. All the data were analysed by software JMP10 and a one-way ANOVA test was used for comparing the difference between background and bird perch site.

\section{Results}

Overall, we observed 58 birds perching either on branches or on grasses. Ravens comprised 65 per cent of these birds: most were on branches but two were on grasses. Starlings took up 9 per cent of the whole sample and all of them were found on grasses. Rosellas and robins were all found on branches, which took up 14 per cent and 12 per cent respectively. No bird was found on rocks or shrubs and therefore the temperature and light intensity of these substrates was discarded.

When considering the temperature preference of birds, a histogram was made for comparison (Figure 1). The ANOVA showed that, on both the cold and warm days, the mean temperature of the perch site and background were not statistically different. The $P$ value for the warm day was 0.1243 and the similarity was also observed in the shape of the histogram. On the warm day, the temperature distributions of perch site and environment were all positively skewed with a highest frequency of 
$15-20^{\circ} \mathrm{C}$. Although the mean temperature for cold days was not different, the distribution patterns of temperature in perch site and environment were. Despite a normally distributed background temperature, birds on the cold day had almost equal likelihood to occur in all positions on the temperature gradient, which means the selection of perch site temperature was non-random (Figure 1).

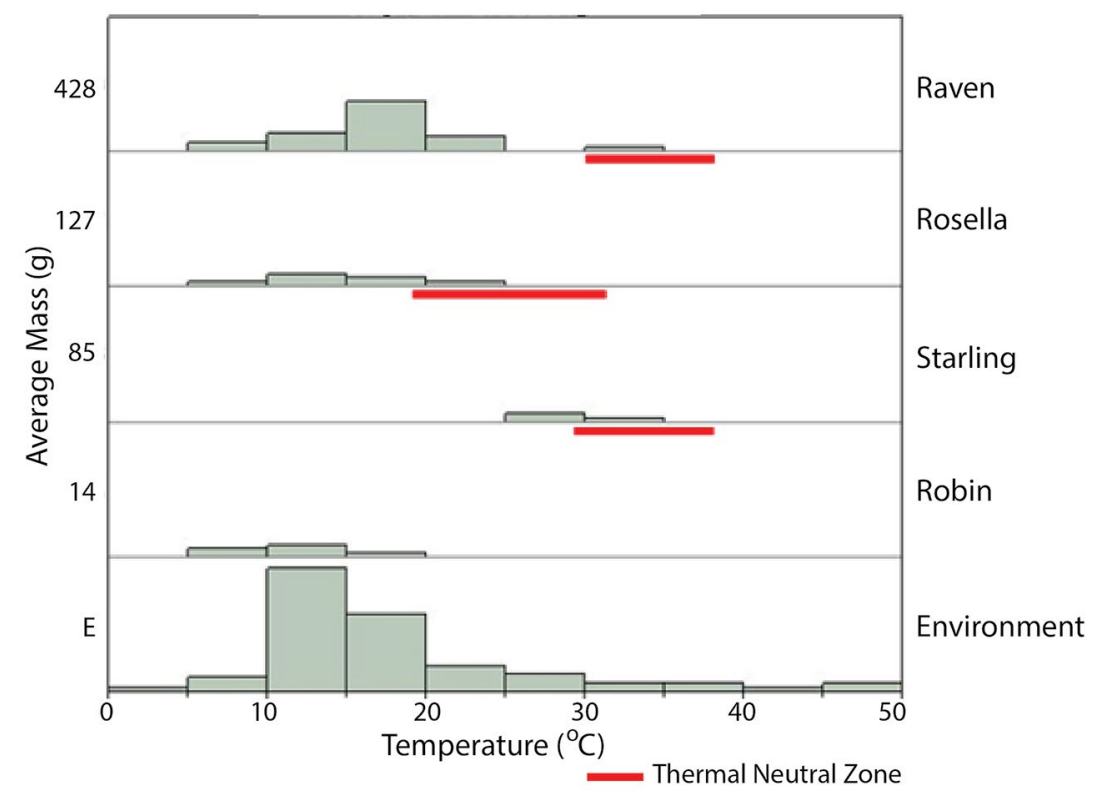

Figure 2: Frequency histogram of temperature by species. Temperature was divided into $5^{\circ} \mathrm{C}$ intervals (on $\mathrm{x}$-axis) and the height of the column represents the frequency of the object temperature. The average mass of each species is shown on the y-axis. The bottom plot shows the temperature distribution for the environment. The red bars indicate the thermal neutral zone of each species (referenced in the Method section). In total, we observed 42 ravens, 8 rosellas, 3 starlings and 6 robins perching. The three species with red bars show perching behaviour as a response when they are out of their thermal neutral range.

Source: Authors' data.

The preference of temperature also varied among species (Figure 2). The histogram indicated that both robins and rosellas have no preference for temperature of perch site since the distributions are very similar to the distribution of temperatures in the environment. ANOVA confirmed the observation with $P$ values of 0.0916 for robins and 0.2933 for rosellas. Starlings occurred in the place where temperature was higher 
than background and the ANOVA test is significant $(P=0.0232)$ yet the result needs to be discussed as the habitat of starlings is grassland, which is much warmer than other background objects. Although the ANOVA test for ravens was not statistically significant $(P=0.8602)$, the temperature distribution was different. The perch site temperature of ravens was normally distributed with the highest frequency ranging in $15-20^{\circ} \mathrm{C}$ while the ambient temperature was positively skewed and most likely to be $10-15^{\circ} \mathrm{C}$. Consequently, ravens had a preference for warmer sites to help with thermoregulation. When comparing the frequency with thermal neutral zone (referenced in the Method section), all the birds except robins tended to perch more when the ambient temperature was lower than their lower critical temperature.

Temperature distribution of microenvironment was also analysed. The distributions of perch site temperature were highly similar to the temperature of the surroundings, which was measured with a thermal camera. The ANOVA test also suggested that they were not statistically significant with $P$ values of 0.9443 for cold days and 0.2835 for the warm day. As a result, alpine birds have no preference on particular warmer branches or grasses.

The comparison of light in perch site with environment during the cold and warm days indicated that there was no significant difference with $P$ value of 0.9255 for cold days and 0.0740 for warm day. The $P$ value for the warm day is very close to 0.05 and the ANOVA test indicated a slightly higher light level in perch site. The light preference differed among species (Figure 3). Similar to temperature preference, robins and rosellas had no predilection on light ( $P$ value of 0.9591 for robins and 0.6835 for rosellas) while starling only stayed in high-light grassland ( $P=0.0022$, significant). The $P$ value for ravens was 0.3188 , which was not significant. However, when comparing to light level of environment, which was mostly below $25 \mathrm{Klux}$, ravens equally perched in the place that had light intensity below 150 Klux, which suggested that ravens preferred brighter sites.

Behaviours like puffing and sitting were also found when birds were perching. The frequencies of these behaviours as well as the position of perch site were analysed and shown as a bar chart (Figure 4). On cold days, no bird perched in the shade and the frequencies of puffing and sitting were much higher. Smaller birds like robins preferred puffing regulation (50 per cent) on cold days and perching in the sun ( 60 per cent) on the warm day, whereas larger birds preferred sitting on cold days. 


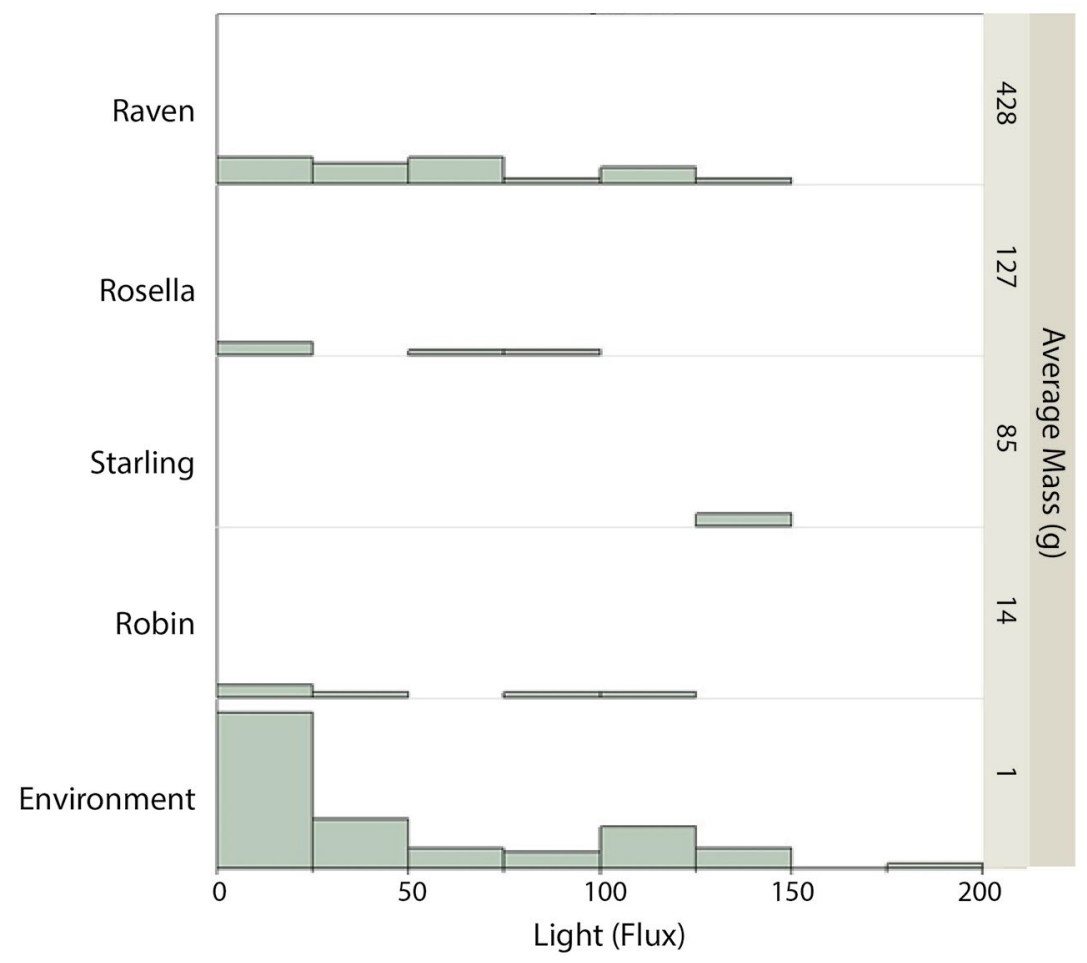

Figure 3: Frequency histogram of light intensity in species. Light intensity was divided into $25 \mathrm{Klux}$ intervals (on x-axis) and the height of the column represents the frequency. The average mass of each species is shown on the $y$-axis. The bottom histogram (1 $\mathrm{g}$ in average mass) represents the light frequency of environment. In total we observed 42 ravens, 8 rosellas, 3 starlings and 6 robins perching. Robins and rosellas show no preference for perch site while starlings perch in high light area. Ravens have a preference for more illuminated sites.

Source: Authors' data.

\section{Discussion}

Overall, the results show that only ravens met our prediction of preference for a warm and high light environment. Starlings also significantly chose warm and light perching sites, although the sample size was very small. The hypothesis of particular preference for smaller birds was not supported and the results show that exposure to higher temperatures and light was not linked to body mass. Although there was no particular trend, the selection of temperature on cold days and light on the warm day was not 
random, and birds did need thermoregulatory behaviours, like puffing and sitting, to help regulate body temperature when they were out of their thermal neutral zone.

The results for the perch site of starlings indicate a statistically significant preference for higher temperature and illumination, yet the difference may not due to thermoregulation. The sample size of starling in our study is very small and limited. All the starlings in the data were found in grasslands that had higher temperatures and light intensity than branches due to sunlight exposure. Other studies confirm that, although considered to be a generalist, starlings in non-urban areas have higher incidence in grasslands than other habitats (Mennechez and Clergeau 2006). Therefore, the high frequency of starlings appearing at high light and warm places is also possibly a result of other factors like nesting and foraging behaviour. Nevertheless, other research also found evidence of seasonal thermoregulation in the red-winged starling, which suggests that starlings in winter have higher basal metabolic rate, resting metabolic rate and body mass to deal with cold environment (Chamane and Downs 2009). The behavioural thermoregulation of the starling is not well known and starlings probably prefer to regulate body temperature physiologically. Future experiments like starling-grassland specific observation are suggested.

Neither robins nor rosellas show preference for warmer and brighter perching sites, which may be due to the risk of predation. The trade-off between thermal benefit and predation risk is always the main factor that impacts thermoregulation behaviour. Several researchers have found that birds appear more responsive to the risk of being preyed upon. VillénPérez et al. (2013) suggest that the influence of predation is three times higher than temperature preference for woodland birds in winter and there is no light predilection. Furthermore, some wintering birds even have a preference for shaded areas when dealing with predation risk and change their orientation to avoid glare effect when they are in the sun, which indicates that predation is more important than radiation benefit (Carr and Lima 2014). Therefore, robins and rosellas may consider more about being found by predators and choose not to perch in a warm place with high sunlight. Our study was done in early summer when the predators were more active than during the winter period and so the predation risk was higher, which further reduced the chance of birds perching on warmer and lighter sites. However, for ravens, although large body and 
black colour make the raven easier to see, there are few potential predators and therefore ravens can utilise radiation without worrying about being eaten.

Another possibility is that the two species, rosella and robin, may prefer to regulate body temperature physiologically rather than behaviourally, yet the physical changes of the birds during cold periods are not well known. Future study of physiological thermoregulation in these small birds is needed. Finally, alpine birds may have acclimated to the cold environment. Solomonov et al. (2009) suggest that birds in a cold environment have a lower metabolic rate and less body temperature stability. Thus the robin, rosella and even raven in the alpine area may have altered their thermal neutral zone to a lower level for cold resistance. The temperature in early summer may not be cold enough for alpine birds to invest in behavioural thermoregulation.

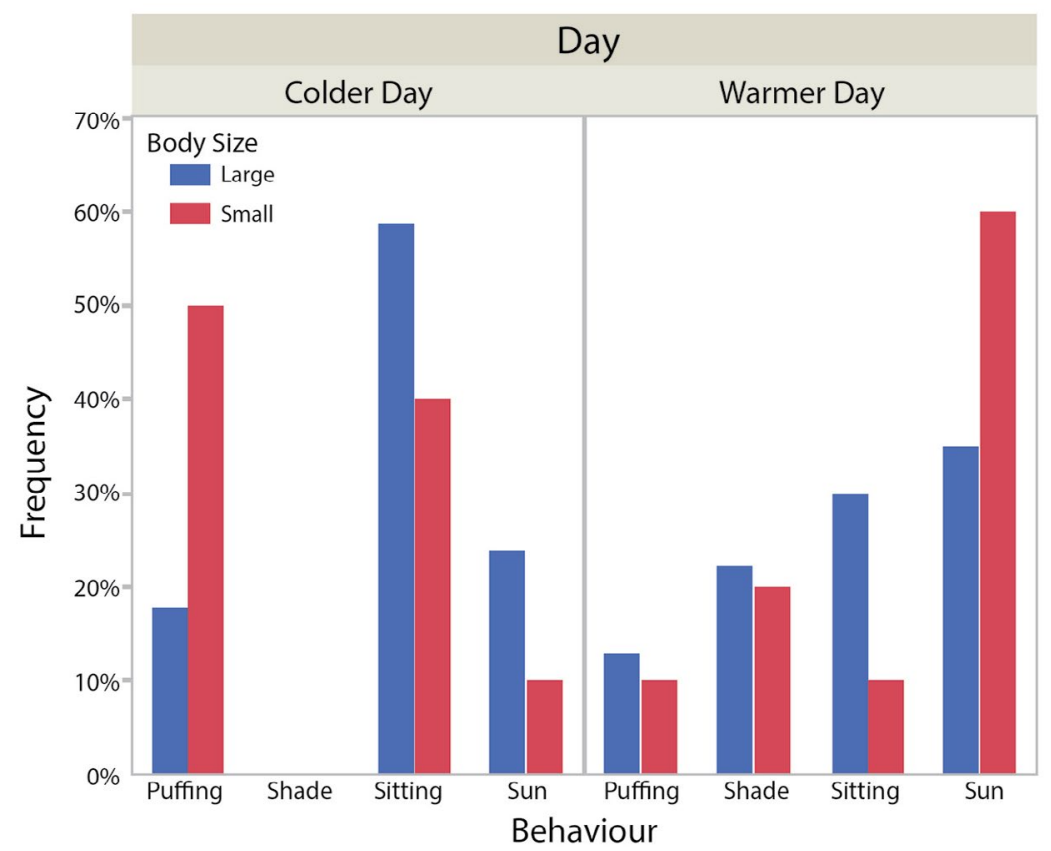

Figure 4: Frequency bar chart of thermoregulation behaviour during warm and cold days. Puffing is the behaviour where birds fluff feathers up and sitting means the bird crouching and hiding their feet. Shade and sun refers to the position where the birds perch. No bird stayed in shade on the cold days and behaviours like puffing and sitting are more likely to be observed on colder days.

Source: Authors' data. 
Apart from perching, behaviours like sitting and puffing that we observed are also found in other research. Carr and Lima (2012) identified that wintering birds conserve heat by changing posture like minimising leg exposure and significant ptiloerection, which we recorded as sitting behaviour. These behaviours can be considered as advanced thermoregulation compared to perch-site choice, as sitting and puffing are more active ways to conserve heat. Also, these behaviours do not require solar radiation to gain extra heat, which decreases the risk of being found by predators under the sunlight. Other studies suggest that the surface choice of red-necked nightjars changes due to ambient temperature (Camacho 2013). They are more likely to choose warmer surfaces to land on in cooler weather, which we also found in our study when comparing the temperature preference of birds on warm and cold days.

Future work is highly recommended to refine our results. Firstly, there were measuring errors in this study due to either the measuring instruments themselves or the non-reachable sites. Light meter readings fluctuated due to the change of light intensity when clouds moved. Most of the time birds perched at branches that were high up in the tree and the assumption that the light and temperature of the perch site was same as that of down beneath may be inaccurate. On the top of the tree there was more sunlight and so the temperature and light intensity should be higher than ground, and thermal camera may also have bias as the reading became inaccurate when the objects in the photo was actually far away. Thus, more accurate instruments should be used for further studies. Also, due to the shortage of statistical skills, we used an ANOVA to analyse the differences, which may not be the most appropriate statistical method. The true distributions of temperature and illumination are not consistent with our assumption of normal distribution. And the range of both temperature and light intensity of perch site must be within the range of background data, which makes it hard for an ANOVA test to compare the differences of the modes. Non-parametric methods may be more suitable in this case as the frequencies were not normally distributed. In addition, perching that we observed may not be only due to heat conservation, but also because of feeding and guarding the nest. Thus, longer observation for every bird is suggested for future experiments to eliminate other factors that may cause birds to stay in one place.

This study was done in three days due to time limitation, and a wider range of temperatures is needed to improve the understanding of thermoregulation of alpine birds. We suggest a whole-year observation. 
Furthermore, factors like wind speed and orientation of birds can also be measured and analysed so that the perch behaviour can be better explained. The impact of predation can be examined by analysing the potential shelter sites in the surroundings. If the influence of predation risk for alpine birds is more important than radiation benefit, shelter and coverage for them is indispensable, which may indicate that people should avoid destroying the potential shelter for birds when developing the tourist industry. The thermoregulation behaviour we observed indicates that even in early summer the temperature is still unfavourable for alpine birds. Ravens prefer warm perch sites and other birds change postures to conserve heat, which provides us a broad view of thermoregulatory strategy in alpine birds. If the alpine region becomes warmer due to climate change, the birds there will possibly be better able to adapt to the changed environmental conditions.

\section{Acknowledgements}

We are grateful to Iliana Medina for supervising, and to Adrienne Nicotra and other BIOL2203 staff for running this wonderful course.

\section{References}

Camacho C (2013) Behavioural thermoregulation in man-made habitats: Surface choice and mortality risk in red-necked nightjars. Bird Study 60: 124-30. doi.org/10.1080/00063657.2012.753400

Carr J, Lima S (2014) Wintering birds avoid warm sunshine: Predation and the costs of foraging in sunlight. Oecologia 174: 713-21. doi. org/10.1007/s00442-013-2804-7

Carr JM, Lima SL (2012) Heat-conserving postures hinder escape: A thermoregulation-predation trade-off in wintering birds. Behavioural Ecology 23: 434-41. doi.org/10.1093/beheco/arr208

Carrascal LM, Díaz, JA, Huertas DL, Mozetich I (2001) Behavioural thermoregulation by treecreepers: Trade-off between saving energy and reducing Crypsis. Ecology 82: 1642-54. doi.org/10.1890/00129658(2001)082[1642:BTBTTO]2.0.CO;2 
Chamane SC, Downs CT (2009) Seasonal effects on metabolism and thermoregulation abilities of the red-winged starling (Onychognathus morio). Journal of Thermal Biology 34: 337-41. doi.org/10.1016/j. jtherbio.2009.06.005

DiBona GF (2003) Thermoregulation. American Journal of Physiology Regulatory, Integrative and Comparative Physiology 284: R277-R279. doi.org/10.1152/ajpregu.00571.2002

Dmi'el R, Tel-Tzur D (1985) Heat balance of two starling species (Sturnus vulgaris and Onychognathus tristrami) from temperate and desert habitats. Journal of Comparative Physiology B 155: 395-402. doi. org/10.1007/BF00687484

Durfee S (2008) Review: Skin: A Natural History by Nina G. Jablonski. The American Biology Teacher 70: 56. doi.org/10.2307/30163197

Dzialowski, EM, O’Connor, MP (2001) Physiological control of warming and cooling during simulated shuttling and basking in lizards. Physiological and Biochemical Zoology: Ecological and Evolutionary Approaches 74: 679-93. doi.org/10.1086/322929

Fernández-Juricic E, Deisher M, Stark AC, Randolet J (2012) Predator detection is limited in microhabitats with high light intensity: An experiment with brown-headed cowbirds. Ethology 118: 341-50. doi.org/10.1111/j.1439-0310.2012.02020.x

Hafez ESE (1964) Behavioural thermoregulation in mammals and birds. International Journal of Biometeorology 7: 231-40. doi.org/10.1007/ BF02187455

Marder J (1973) Body temperature regulation in the brown-necked raven (Corvus corax ruficollis) - II. Thermal changes in the plumage of ravens exposed to solar radiation. Comparative Biochemistry and Physiology Part A: Physiology 45: 431-40. doi.org/10.1016/0300-9629(73)90450-7

McNab BK, Salisbury CA (1995) Energetics of New Zealand's temperate parrots. New Zealand Journal of Zoology 22: 339-49. doi.org/10.1080 /03014223.1995.9518050

Mennechez G, Clergeau P (2006) Effect of urbanisation on habitat generalists: Starlings not so flexible? Acta Oecologica 30: 182-91. doi. org/10.1016/j.actao.2006.03.002 
Solomonov NG, Anoufriev AI, Isayev AP, Nakhodkin NA, Solomonova TN, Yadrikhinskiy VF, Mordosova NI, Okhlopkov IM (2009) 128. Thermoregulation of cold-adapted birds and mammals of Yakutia (north-east of Siberia). Cryobiology 59: 406. doi.org/10.1016/j. cryobiol.2009.10.142

Tansey EA, Johnson CD (2015) Recent advances in thermoregulation. Advances in Physiology Education 39: 139-48. doi.org/10.1152/ advan.00126.2014

Tattersall GJ, Andrade DV, Abe AS (2009) Heat exchange from the toucan bill reveals a controllable vascular thermal radiator. Science 325: 468-70. doi.org/10.1126/science. 1175553

Toro-Velasquez PA, Bícego KC, Mortola JP (2014) Chicken hatchlings prefer ambient temperatures lower than their thermoneutral zone. Comparative Biochemistry and Physiology Part A: Molecular \& Integrative Physiology 176: 13-19. doi.org/10.1016/j.cbpa.2014.06.008

Villén-Pérez S, Carrascal LM, Seoane J (2013) Foraging patch selection in winter: A balance between predation risk and thermoregulation benefit. PLoS ONE 8: e68448. doi.org/10.1371/journal.pone.0068448

Zhao Z-J, Chi Q-S, Liu Q-S, Zheng W-H, Liu J-S, Wang D-H (2014) The shift of thermoneutral zone in striped hamster acclimated to different temperatures. PLoS ONE 9: e84396. doi.org/10.1371/ journal.pone. 0084396 
This text is taken from Researching functional ecology in Kosciuszko

National Park, edited by Hannah Zurcher, Chia Ming-Dao, Michael Whitehead and Adrienne Nicotra, published 2017 by ANU eView, The Australian National University, Canberra, Australia. dx.doi.org/10.22459/RFEKNP.11.2017.11 